\title{
Geomatics \& Participation Summer School 2016 - Developing mobile mapping apps to encourage citizen participation in nature conservation
}

\author{
Gertrud Schaab $^{\mathrm{a}, *}$, Serena Coetzee ${ }^{\mathrm{b}}$, Christian Stern $^{\mathrm{a}}$, Victoria Rautenbach ${ }^{\mathrm{b}}$ \\ ${ }^{a}$ Faculty for Information Management and Media, Karlsruhe University of Applied Sciences, Karlsruhe, Germany, \\ gertrud.schaab@hs-karlsruhe.de,christian.stern@hs-karlsruhe.de \\ ${ }^{b}$ Centre for Geoinformation Science, Department of Geography, Geoinformatics and Meteorology, University of Pretoria, Pretoria, \\ South Africa, serena.coetzee@up.ac.za,victoria.rautenbach@up.ac.za \\ * Corresponding author
}

\begin{abstract}
Geospatial tools in a Web 2.0 environment can encourage citizens to engage with and influence their environment through online participation. In the field of geomatics, today's students have to develop competencies in current technologies and learn how to adapt to continuously and rapidly changing technologies and applications. At the same time, we live in a globalized world where we increasingly deal with people from different backgrounds or have to commute to unknown places and environments for work. In this paper, we report about the experiences of students and lecturer participants from Germany and South Africa in a summer school on geomatics and participation, held in Karlsruhe, Germany, in July 2016. The starting point was to learn about nature conservation in Germany, particularly about the Rhine floodplains close to Rastatt. Mobile mapping apps were developed for this area with the aim of supporting conservation efforts. Confronting the participants with a new geographic area, a software development environment unknown to them and group work with participants from both universities has led to interesting insights beyond getting to know the partner university. From an evaluation of the summer school by participants, it was evident that the summer school succeeded in raising interest for participation in the student exchange programme and that participants expect clear guidance on the objectives of different activities. The balance between socializing and work provides a unique atmosphere for effective teaching and working, making a summer school such an enjoyable experience for students and lecturers.
\end{abstract}

Keywords: participation, mobile mapping app, cartography, geomatics, education

\section{Introduction}

Rapidly changing technologies provide new opportunities in the field of geomatics. Among these, geospatial tools in a Web 2.0 environment can encourage citizens to engage with and influence their environment through online participation. Participatory sensing refers to data collection using the modern mobile phones as sensors. Citizens volunteer and use their own mobile devices, such as smartphones, to capture and share data of incidents or phenomena of common interest (Mousa et al., 2015). According to Reichenbacher (2012), maps are the mostused information on the mobile Internet. This development has led to the term 'geoinformation society' for today's society where maps and other geomedia are used to structure information and to construct spatial meaning (Vogler, 2016).

Today's students have to develop competencies in current technologies and learn how to adapt to continuously changing technologies. At the same time, we live in a globalized world where we increasingly deal with people from different backgrounds on a daily basis or have to commute to other places and unknown environments for work. The wide range of key geospatial technologies to be covered within a study programme related to geographic information science and technology (GIS\&T) has been further expanded for the revision of the GIS\&T Body of Knowledge (Rip et al., 2014). Fairbairn (2013) points to the ever increasing variety of data, tools and procedures available today and thus requiring the related skills to be taught in the field of cartography. Among these, mobile cartography and technologies supporting the collection of crowdsourced data are gaining importance.

In this paper, we report about the experiences of students and lecturer participants from Germany and South Africa in a summer school on geomatics and participation, held in Karlsruhe, Germany, in July 2016. The students developed four mobile mapping apps for participatory sensing in the Rastatter Rheinaue, a nature conservation area $25 \mathrm{~km}$ south of Karlsruhe. The summer school was part of a larger project aiming to bring together students from BadenWürttemberg in Germany and students from South Africa. The ultimate goal is to start a long-term partnership between Karlsruhe University of Applied Sciences (HsKA) and the University of Pretoria (UP), for example, through a regular student exchange programme.

In section 2, we provide background information about the project. Section 3 describes the 2016 Geomatics \& 
Participation Summer School programme and provides an evaluation by relating experiences of lecturers and students. Section 4 concludes with a summary of experiences and lessons learnt.

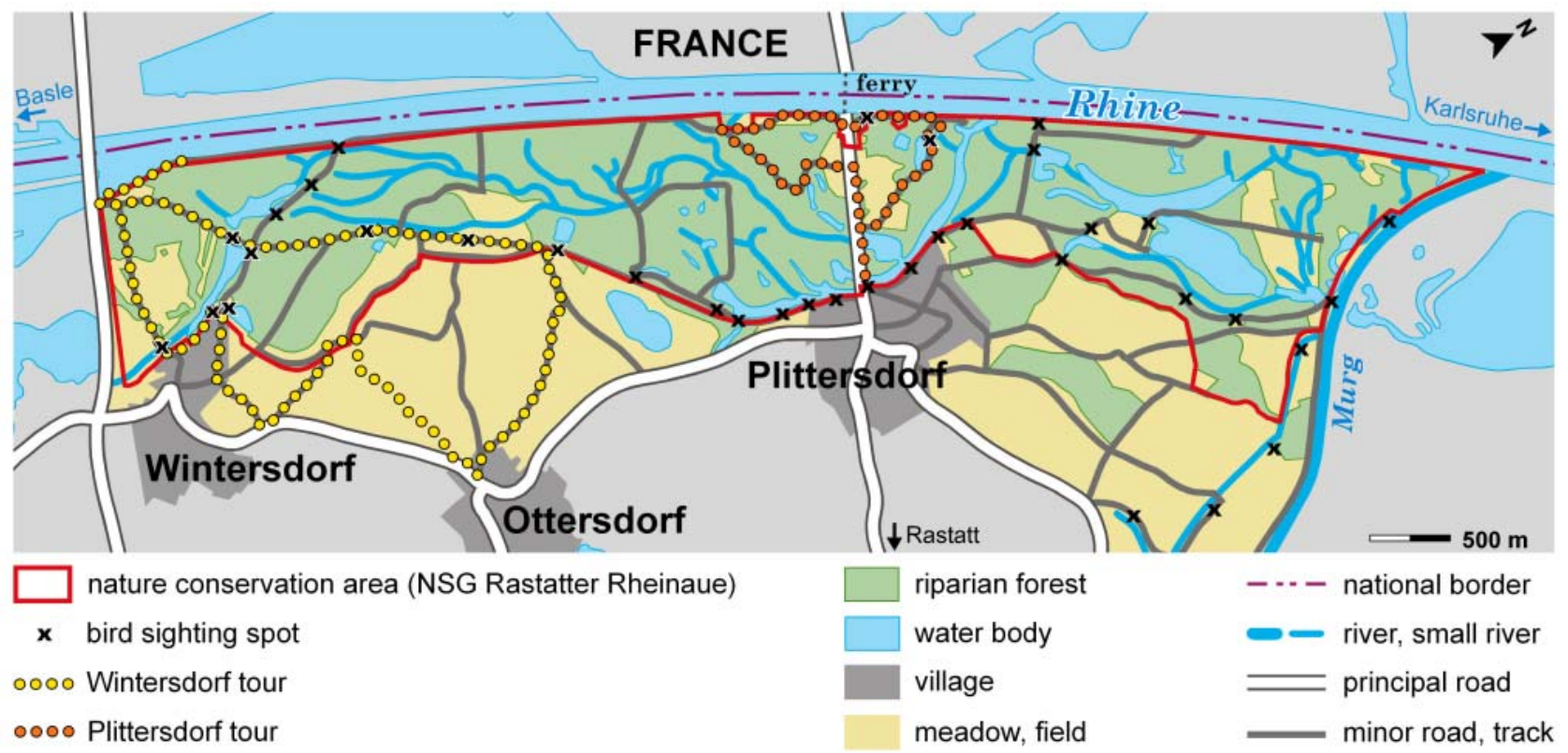

Figure 1. The study area of the 2016 Geomatics \& Participation Summer School

\section{Project Background}

International mobility of students and lecturers is widely encouraged in universities all over the world, also in Germany and South Africa. While Baden-Württemberg, and especially the Karlsruhe region, is known as a region of technology and innovation, South Africa is a so-called emerging country. South Africa has the second-most competitive economy in Africa (Schwab and Sala-iMartín, 2015) and leads the continent in many ways. However, interest among HsKA students to participate in student exchange to Africa is fairly poor. On the other hand, many South African students do not have the financial means to participate in an exchange programme and are not always aware of bursary opportunities for student exchange, except those provided by the Deutscher Akademischer Austauschdienst (DAAD $\left.{ }^{1}\right)$.

The aim of this project, funded by the Baden-Württemberg Stiftung (BWS), is to raise awareness and to encourage students from both countries to participate in student exchange programmes, while at the same time providing students with an opportunity to benefit from the combined expertise at the two universities and learning how to develop mobile mapping apps for participatory sensing in application fields typical for the country visited. To achieve this aim, the following activities are planned for the project: 1) research visits by HsKA and UP postgraduate students to the respective other university; 2) practical semesters by HsKA students at South African organizations; 3) course work semester by UP students in
Karlsruhe; and 4) two summer schools, one in Karlsruhe and one in Pretoria (which will actually be a winter school).

The aim of the summer and winter schools is to allow students to experience the application of novel geomatics technologies, and to highlight and reflect on the differences in the relevance and acceptance of citizen participation in Europe and in Africa. The summer school in Karlsruhe focused on 'Environmental Protection by Integrating Citizens'. The winter school in Pretoria will focus on 'Planning in Informal Settlements'. We hope that through the summer and winter schools, South Africans will positively experience Baden-Württemberg as a study and research location. In return, the German students have the opportunity to adjust any biased opinions they may have about living and working in Africa.

Very different experiences regarding 'participatory sensing' are expected from the summer school in Karlsruhe and the winter school in Pretoria. In Germany, the focus was on exploring possibilities for stronger participation from citizens in nature conservation (cp. McKinley et al., 2016), i.e. in the Rhine floodplains close to Rastatt (the nature conservation area 'NSG Rastatter

${ }^{1}$ www.daad.de 


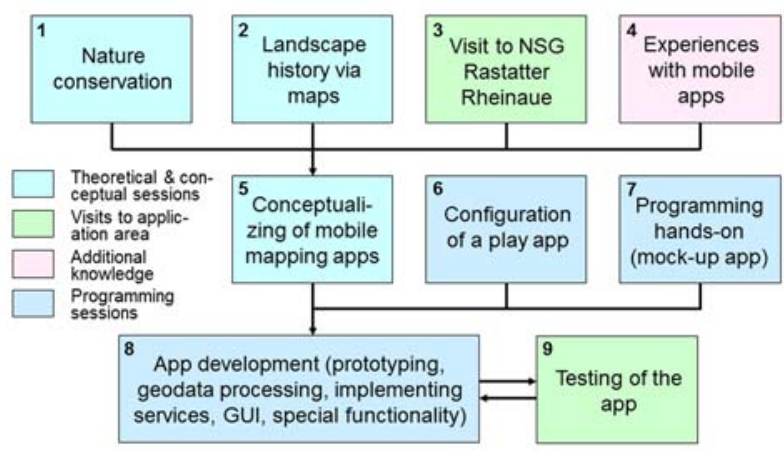

Figure 2. Setup of the 2016 Geomatics \& Participation Summer School (not covering additional socializing activities)

Rheinaue'; Fig. 1). In South Africa, 'participatory sensing' presents the opportunity to empower citizens by influencing their environment through participation (OGP South Africa, 2011). The study area will be the informal settlement, 'Alaska' in Pretoria East.

\section{Geomatics \& Participation Summer School 2016 in Karlsruhe, Germany}

\subsection{Setup}

The 2016 summer school accommodated 18 participants: four lecturers from HsKA and UP, eight UP BScHons Geoinformatics students and six HsKA International Geomatics Master students. Three of the HsKA students grew up in Germany and completed their Bachelor degrees in Germany, one having spent two academic semesters in Namibia; the other three had lived in Karlsruhe for almost a year prior to the summer school, but had completed their first degrees in Ghana, Pakistan and Sudan respectively. Considering the diverse backgrounds and experiences of participating students, it was opted to use a software development environment none of the students had worked with before. Esri's AppStudio for ArcGIS ${ }^{2}$ offers a do-it-yourself (DIY) tool for developing cross-platform mapping apps, facilitated through out-of-the-box templates. We were further aware that app development with all features thoroughly tested could not to be achieved within a two-week summer school. Therefore we aimed at gaining experiences beyond developing the perfect app, such as programming in a new development environment, learning about nature conservation and socializing in a diverse group.

Fig. 2 reveals the setup, comprising a range of activities. The background for conceptualizing potential mobile mapping applications (5) was provided by a visit to the NSG Rastatter Rheinaue, including a guided tour by the local forester and an environmentalist, as well as a canoeing trip (3); theoretical thoughts on nature conservation and its values (1); plus an introduction to the landscape's history by means of old maps (2) in combination with the participants' own experiences with mobile apps (4). The students had many interesting ideas for apps, but due to time constraints, we had already prepared four application concepts based on discussions with the people on the ground. With the limited time frame in mind, all the necessary geospatial data and information had been gathered ahead of the summer school. For the students to get to know the DIY tool and to start programming, play apps were developed via mere configuration (6), followed by a few sessions of hands-on programming of a mock-up app (7). For the actual app development, we concentrated on app design (prototyping, graphical user interface (GUI) design), the use of map services, and learning how to implement different kinds of functionality in the new tool (8). First testing of the app in the nature conservation area provided feedback on the readiness of the apps (9). Besides the above mentioned activities, the summer school offered a broad socializing programme for getting to know each other and for experiencing local attractions and activities. Spontaneously, we also included a brief map reading exercise after the first day in the Rastatter Rheinaue. Students received a map of the study area (during the visit, they had paid limited attention to map information about the area) and had to work out where they had been on the day before.

\subsection{Study area and proposed apps}

At the end of the last glacial period of the ice age (Pleistocene), the Rhine started to dig its way into the socalled low terrace consisting of gravel (detritus) and sand deposited by the Rhine and its tributaries during the glacial period. This resulted in a constantly changing landscape of widely arching meanders in what is today called the Upper Rhine valley. The original natural floodplains experienced their largest change due to the Rhine Correction, following the plans of J.G. Tulla in the 19th century, which forced the river into reinforced banks, thus decreasing the risk of flooding, improving soil productivity, and facilitating ship traffic. However, it substantially changed the entire hydrological and ecological situation of the Rhine floodplains. Floodplains with their natural vegetation have become a rather limited feature along the Rhine (Musall, 2015).

One of the few remaining floodplains is the nature conservation area, Rastatter Rheinaue, with a size of about 850 ha. It stretches out for $7.5 \mathrm{~km}$ along the eastern side of the canalized Rhine, approx. $25 \mathrm{~km}$ south of Karlsruhe, with France on the opposite side of the river. Since 1984, the area has been under protection as a Naturschutzgebiet (NSG); in 2000, it became part of the Europe-wide Natura $2000^{3}$ network; and since 2008 , it has been listed as a cross-border Ramsar ${ }^{4}$-site. The area is covered by thick riparian forests, large cut-off meanders or oxbow lakes, as well as open meadows. It is in particular known for its changing water levels of as much as $6 \mathrm{~m}$ in a year and as a result, offers diverse habitats for water birds, amphibians, fish and insects (Regierungspräsidium Karlsruhe, 2015).

\footnotetext{
${ }^{2} \mathrm{http}: / /$ appstudio.arcgis.com

${ }^{4}$ http://www.ramsar.org/

${ }^{3} \mathrm{http}$ //natura.org/
} 


\begin{tabular}{|c|c|c|c|c|}
\hline App & Monitoring water birds & Watch the water birds & $\begin{array}{l}\text { Monitoring nature con- } \\
\text { servation / failure }\end{array}$ & $\begin{array}{l}\text { Tracing historical land- } \\
\text { scape changes }\end{array}$ \\
\hline Logos & & & & \\
\hline $\begin{array}{l}\text { Geographical ex- } \\
\text { tent }\end{array}$ & Entire NSG and beyond & Same as app 1 & Along Plittersdorf tour & Along Wintersdorf tour \\
\hline Purpose / aim & $\begin{array}{l}\text { Collecting comparable } \\
\text { observation data over } \\
\text { time }\end{array}$ & $\begin{array}{l}\text { Simplifying and adapting } \\
\text { app } 1 \text { for children }\end{array}$ & $\begin{array}{l}\text { Offering information and } \\
\text { pastime activities to visi- } \\
\text { tors }\end{array}$ & $\begin{array}{l}\text { Supporting of tracing his- } \\
\text { toric features hidden in } \\
\text { landscape }\end{array}$ \\
\hline $\begin{array}{l}\text { App to store / col- } \\
\text { lect }\end{array}$ & $\begin{array}{l}\text { Location, \# of birds, spe- } \\
\text { cies, environmental con- } \\
\text { ditions, etc. }\end{array}$ & $\begin{array}{l}\text { Same as app } 1 \text {, plus re- } \\
\text { port by user on activities }\end{array}$ & $\begin{array}{l}\text { Location, conservation } \\
\text { success / failure, photo / } \\
\text { sound, etc. }\end{array}$ & $\begin{array}{l}\text { Location, photo of situa- } \\
\text { tion, comment for photo, } \\
\text { etc. }\end{array}$ \\
\hline $\begin{array}{l}\text { Special functionali- } \\
\text { ties }\end{array}$ & $\begin{array}{l}\text { Geotargeting (sighting } \\
\text { spot), geofencing (permit- } \\
\text { ted roads) }\end{array}$ & $\begin{array}{l}\text { Gamification feature, } \\
\text { sending-off report }\end{array}$ & $\begin{array}{l}\text { Remaining time estimates } \\
\text { to ferry, geofencing } \\
\text { (roads) }\end{array}$ & $\begin{array}{l}\text { Automatic orientation of } \\
\text { map, display of contribu- } \\
\text { tions by others, geofenc- } \\
\text { ing (roads) }\end{array}$ \\
\hline Available data & $\begin{array}{l}\text { Sighting points, list of } \\
\text { bird species with pre- } \\
\text { ferred habitat and occur- } \\
\text { rence, photo per bird }\end{array}$ & $\begin{array}{l}\text { As app } 1 \text { but drawing per } \\
\text { bird, idea for game, top- } \\
\text { ics for report }\end{array}$ & $\begin{array}{l}\text { Categories of conserva- } \\
\text { tion successes / failures, } \\
\text { places to buy snacks / } \\
\text { beverages }\end{array}$ & $\begin{array}{l}\text { Historical geodata layers, } \\
\text { historical background in- } \\
\text { fo, example photos }\end{array}$ \\
\hline
\end{tabular}

Table 1. The proposed mobile mapping apps for NSG Rastatter Rheinaue and their functionalities

The aim of the summer school was to develop mobile mapping apps to encourage citizen involvement in the NSG Rastatter Rheinaue. By targeting four apps (see Table 1), three to four students from both the HsKA and UP, could jointly work on one app. App 1 (Monitoring water birds) supports the monitoring of water birds by those keen on contributing to their regular counting. Water birds are widely visible and distinguishable and therefore a rather motivating target for participation. To encourage children to also participate, App 2 (Watch the water birds) is a modified version of the first app with more easily recognizable depictions of the birds. In order to keep the kids attracted, a gamification component had to be included, as well as an option to prepare a report of the excursion's activities. App 3 (Monitoring nature conservation / failure) offers information and pastime

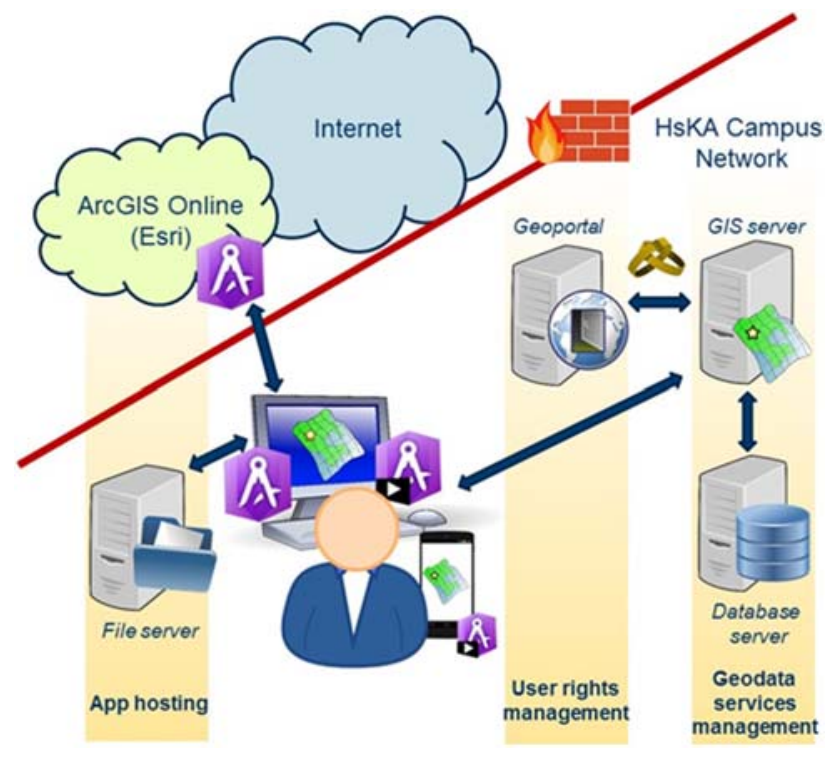

${ }^{5} \mathrm{http}: / /$ doc.arcgis.com/en/appstudio/

${ }^{6} \mathrm{https} / / /$ www.qt.io/ide/ activities to visitors of the most visited area of the Rastatter Rheinaue, directly adjacent to Plittersdorf and the ferry across the Rhine, while at the same time sensitizing them for nature conservation through active participation. The last app (App 4, Tracing historical landscape changes) provides information for those citizens who like to learn more about the landscape history in the area of Wintersdorf and reasons for the protection status of the Rastatter Rheinaue. By overlaying the current with former situations, and knowing the user's position on the map, a user can reveal and trace historic features still visible in today's landscape.

\subsection{App development}

\subsubsection{Environment used}

The app development took place in HsKA's GIS-lab. The software setup can be traced in Fig. 3. Apart from standard ArcGIS software, the student workplace computers were equipped with AppStudio for ArcGIS (Desktop Edition) ${ }^{5}$ for the app development. This software is bundled with $\mathrm{Qt}$ Creator ${ }^{6}$ for performing the programming tasks, while the former is used to manage the app development and configure the basic settings. To facilitate collaborative work, a file server was offered to the students for sharing their programming code, as well as other resources like geospatial data and teaching materials. For creating the map services to be consumed by the apps, access to an ArcGIS for Server instance with a connected spatial database was provided. This GIS server is federated with the so-called 'geoportal' through which user access and rights are managed. The latter is a server hosting Esri's Portal for ArcGIS ${ }^{7}$ (i.e. Esri's GIS cloud service ArcGIS Online on the premises) and well integrated into the university's IT infrastructure and user management. For testing the apps during the development cycle, AppStudio

\footnotetext{
${ }^{7} \mathrm{http}: / /$ server.arcgis.com/en/portal
} 
Player $^{8}$ was used. This software is available for various platforms (e.g. Windows, Android, iOS) and devices (personal computer, smartphones and other mobile gadgets). Apart from the initial configuring of the play app, when the online version of AppStudio was applied, Esri's ArcGIS Online was needed for the final development step: In order to finalize the apps for the targeted platforms, they were uploaded to Esri's cloud service and compiled there.

\subsubsection{Programming and testing}

To prepare the students for their development task, initial introductory lectures on Qt / $\mathrm{QML}^{9}$ were presented. Next, the students experienced the limits of app configuration, and therefore understood the need for programming, by configuration of given templates in the cloud version of AppStudio. This resulted in so-called 'play apps', i.e. apps that are created in a playful approach for the sake of learning but are rather limited in their functionality. In a next step, the desktop version of AppStudio and programming QML in the Integrated Development Environment (IDE) Qt Creator was introduced to the students by developing a 'mock-up app'. This app, which did not make sense as it combined a calculator with a slippy map in the background, again served the purpose of learning.

With this experience, the students had all necessary means to start off with their group work on a particular app for the NSG Rastatter Rheinaue. The students had to decide whether to start a project from scratch, to extend an existing template or code samples, or to use a mix of both. They worked individually but as a team on the app's core, the map services and the required functionalities (see Table 1). Besides testing their apps on mobile devices in the GIS-lab with fake GPS positions, the students had two opportunities to test the apps under real world conditions in the NSG Rastatter Rheinaue. During the second round

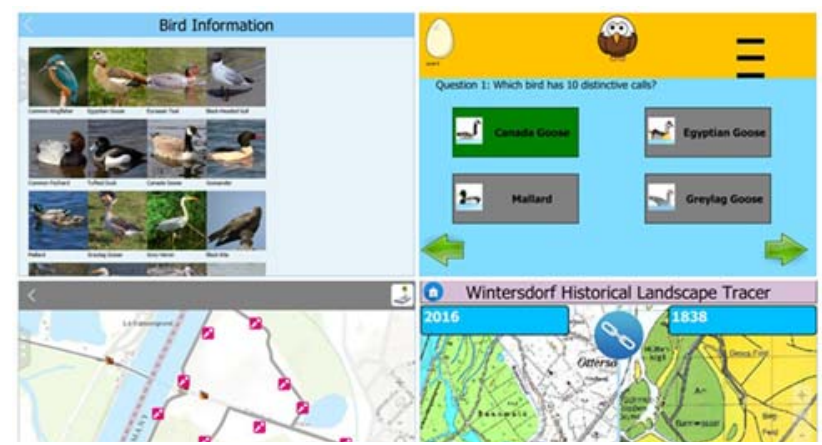

Figure 4. Screenshots of the four mobile mapping apps developed during the 2016 Geomatics \& Participation Summer School. Upper left: Monitoring water birds; upper right: Watch the water birds; lower left: Monitoring nature conservation / failure; lower right: Tracing historical landscape changes

of testing, a group of school pupils from Rastatt tested the apps and provided insight from a user perspective.

\subsubsection{Continuing with the app development}

At the end of the summer school, the core functionality of navigating through the pages worked for all four apps (Fig.

\footnotetext{
8 e.g. https://play.google.com/store/apps/details?id= com.esri.appstudio.player
}

4). App 1 (Monitoring water birds) focused on recording bird sightings by selecting the correct photograph from a list of pictures. For App 2 (Watch the water birds), a playful approach was integrated into the app. For App 3 (Monitoring nature conservation / failure), the students put a lot of effort into making content available. App 4 (Tracing historical landscape changes) allowed the juxtaposition of maps from two distinct time periods. During testing in the field, the students experienced network challenges. Particularly, due to the close border with France, the connection continuously switched between the German and French networks. Therefore, the use of offline map packages for avoiding constant downloading of base map data was identified as a major requirement.

A number of additional tasks remain. Among the still to be implemented specialized functionalities are geofencing and geotargeting, as well as routing for time estimates of reaching destinations like the ferry in Plittersdorf. Storing the data collected over time in a database management system on a server still has to be designed and implemented. Offline availability of (geospatial) data will improve performance. Nevertheless, the user should be informed whenever the app is busy and the user still has to wait for response. To reach a wider audience, eventually the apps should be available in German, and the people on the ground would prefer a similar look and feel (corporate design) across all four apps. The apps still require information (help) pages and should cater for privacy considerations. Security issues to be addressed include possible login functionality. Only after a thorough testing of the apps' functionality and usability has been completed, publishing can proceed, which will lead to a set of further tasks related to licensing, terms and conditions of use, review and approval in the respective mobile stores, as well as marketing and awareness campaigns.

As the mobile mapping apps developed during the summer school are still far from a stage to be confidently made available to citizens, the plan is to pass them on in their current form for further development by students at HsKA. In the last semester of the Bachelor programme on GeoInformation Management, students are expected to work independently on group projects. We expect that most of the remaining tasks can be completed by these students. In addition, documentation for the institutions in Rastatt will thus be available. The plan is to present the outcomes during the 2017 winter school in Pretoria.

\subsection{Evaluation}

\subsubsection{Design}

To evaluate whether we had achieved the aims of the summer school and to understand how participants experienced the new technologies, work in an unknown study area and group work, two focus group discussions were held on the last day of the summer school, one with the UP students and another with the HsKA students. Focus group discussions are suitable for quickly gauging user

\footnotetext{
${ }^{9}$ http://doc.qt.io/
} 
impressions about a topic or concept (Courage and Baxter, 2005).

First, the students received an introduction about the purpose of the focus group discussion. Next, a set of prequestions was asked. The purpose of the pre-questions was to record how many participants had, prior to the summer school, been to the study area; worked with any of the technologies used during the summer school; and studied nature conservation or had been involved in nature conservation in other ways. The discussion itself covered four topics, each with a set of questions: 1) What did you learn during the Summer School? 2) Using maps to get to know the study area, Rastatter Rheinaue; 3) Relevance of citizen participation in Germany / South Africa; 4) Overall impressions and impact.

The questions on the four topics were posed one by one, with a discussion following each. The discussions were recorded and hand-written notes of the most salient points were taken. Participants were informed of the intent to write a report and a conference paper about the focus group discussions, and to use the information gathered as input for planning the winter school in 2017.

\subsubsection{Results and discussion}

Pre-questions. Two HsKA students had visited the study area before (one of them very recently for summer school preparations); two participants had limited experience with App Studio for ArcGIS for mobile app develop-ment, one of them also in regard to Qt and QML; one student had completed modules in nature conservation as part of the Bachelor degree and four of the HsKA students (including the three German students) had been involved in nature conservation projects and/or environmental internships. UP students had completed undergraduate modules in environmental science and geography. These answers to the pre-questions confirm that the summer school exposed the participants to new technologies, a study area that most of them did not know and an application field (nature conservation) that most of them did not know well and some of them had not had any exposure in this field.

Working with new technologies. The UP participants were relieved that the new technology did not present as many barriers as they had expected. Similarly, the HsKA participants were relieved that the summer school did not put them under as much pressure as they had expected; one of the participants even discovered a passion for programming! Participants appreciated getting to know the mobile development process.

UP participants felt that they would have liked to start the summer school with more background knowledge about the objectives and technologies to be used, maybe even acquainting themselves with the software development environment before the summer school started. They also expressed the wish to be informed of the schedule for the day at the beginning of each day (they did receive a schedule for the week). HsKA participants felt that they had not been able to achieve everything that had been expected from them. These observations seem to indicate a need for expectation management. However, the aim of the summer school was to confront them with new tech- nologies, a new study area, a novel application field and working in diverse and cross-cultural teams. The limited information beforehand was intentional and was meant to meet the character of a summer school.

Participants liked the balance between work and socializing during the two weeks. For some participants, spending a whole day in the computer lab was too much (especially without air conditioning in the hot European summer). All of them appreciated the morning and afternoon coffee breaks, which allowed them to relax and to get to know each other.

Working in an unknown study area and an unknown application field. The participants appreciated the value of a map through the exercise in which they had to locate their route on a map on the day after the visit to the study area. Students commented that they did not necessarily pay attention to the maps or their surroundings during the visit, because they were tired and because one of the guides had to speak through an interpreter. From the lecturer perspective, it had been interesting to observe how each group used different 'hooks' in their collective memory of the site visit in order to retrace the route through the study area. In terms of nature conservation, the participants gained knowledge specific to the study area, e.g. about the wild cats in the area and the need for tree species variety. They also learnt to appreciate the amount of effort required for nature conservation. Finally, the students discovered that the landscape in the study area had changed drastically over time.

Group work. Both groups observed that once they had figured out the preferences and skills of different group members, the work in the group was re-distributed to accommodate these preferences and skills. They observed that different perspectives could help to solve a problem, but that negotiation and compromise was sometimes necessary. They noted that individual's preferences for colour schemes varied. Both groups commented on cultural differences, e.g. the UP participants were more relaxed and said 'thank you' more often than necessary in the opinion of the HsKA students.

There were some technical challenges with sharing and integrating the source code of different developers. This is a very real and practical challenge for any group work and a valuable lesson to learn for future studies or careers: one needs to plan and coordinate among group members to successfully collaborate.

Relevance of public participation through mobile apps. The UP students, as well as the HsKA students from outside of Germany, felt that nature conservation was not a priority in their home countries because there were more pressing priorities related to people, safety, peace and security. Also, smartphones are not necessarily as readily available as in Germany, therefore the mobile apps would not be available to many citizens, especially children. The HsKA students commented that mobile apps for public participation were already widely used and that it was important to teach children from an early age how to responsibly use them. 
Achieving the aims. To both groups of students, working with a new technology had been less challenging and stressful than they had feared. This positive experience is something on which they can build in their future careers when confronted with new technologies again. All the students had done group work before and the summer school was another such experience.

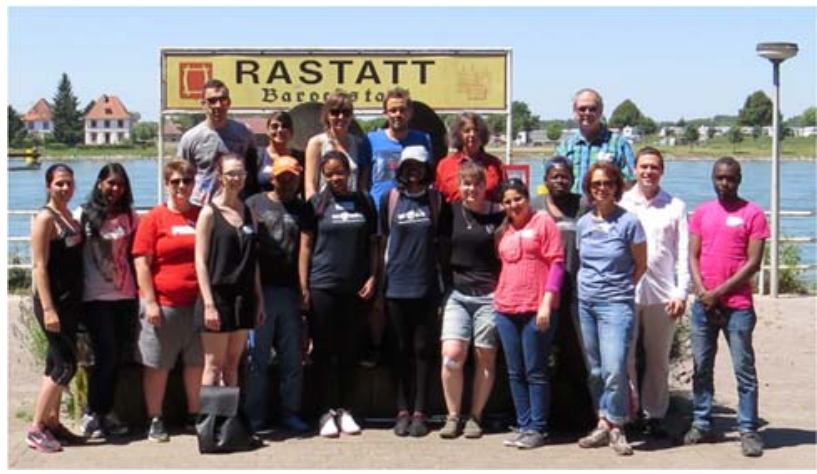

Figure 5. Geomatics \& Participation Summer School 2016 Participants on a visit to the study area

Upon completion of the summer school, at least two HsKA participants showed an interest in visiting South Africa as part of the current project. The summer school therefore succeeded in raising interest among HsKA students in participating in student exchange programmes to South Africa.

On the lighter side, the South African visitors were pleasantly surprised by vehicle traffic actually stopping for them at pedestrian crossings. They missed still water, flavoured water and air conditioning, which they are used to in South Africa, but they loved the local Currywurst and Döner!

\section{Conclusions}

A two-week summer or winter school can be successfully used to expose students to new technologies and application fields, and to provide them with the experience of group work in a new study area with people they have not met before. Careful attention should be given to planning the balance between socializing and work, and to guide participants on the objectives of different activities.

The summer school succeeded in raising interest among HsKA students in participating in student exchange programmes to South Africa, and a similar response is expected from UP students after the winter school. We are grateful for the current funding of the two schools, but realize that such activities will have to continue to sustain the interest in the exchange programme.

Among the lessons learnt from the 2016 summer school is the need to inform participants about objectives before and during the winter school (which may include the intentional lack of information and preparation). When aiming at software development in groups, a version control system should be included in the programming environment to accommodate versioning and integration

\footnotetext{
${ }^{10}$ http://www.iaf.hs-karlsruhe.de/gvisr/project/geomatics-andparticipation.html
}

of source code among group members. For the 2017 winter school we plan to prepare a programme with a similar balance between socializing and work.

The challenge of a summer school with participants from different continents lies in the uncertainty about the skills that the guests will have. The decision to work in mixed groups worked out well and contributed strongly to the beneficial experiences gained by the participants. Preparing and running a summer school involves a diverse range of tasks which definitely requires a dedicated team. However, the effort pays off by the gains from the unique teaching and working atmosphere which is rather different from 'normal' lecturing during the academic semesters.

\section{Acknowledgements}

The project 'Geomatics and Participation - study and research in the tension field between a European technology region and an African emerging country' ${ }^{10}$ is supported by a grant from the Baden-Württemberg Stiftung $^{11}$ (BWS) under the Baden-WürttembergSTIPENDIUM for university students - BWS plus programme ${ }^{12}$. For the Geomatics \& Participation Summer School 2016 we benefitted from the cooperation with City of Rastatt and Environmental Foundation Rastatt.

\section{References}

Courage, C. \& Baxter, K. (2005). Understanding your users: A practical guide to user requirements - methods, tools, \& techniques. San Francisco: Morgan Kaufmann.

Fairbairn, D. (2013). Issues in cartographic education: how and how many? In M. Buchroithner, N. Prechtel, D. Burghardt (Ed.), "Cartography from pole to pole" Selected contributions to the XXVIth International Conference of the ICA, Dresden 2013 (pp. 461-470). Berlin Heidelberg: Springer, Lecture Notes in Geoinformation and Cartography.

McKinley, D.C., Miller-Rushing, A.J., Ballard, H.L., Bonney, R., Brown, H., Cook-Patton, S.C., Evans, D.M., French, R.A., Parrish, J.K., Phillips, T.B., Ryan, S.F., Shanley, L.A., Shirk, J.L., Stepenuck, K.F., Weltzin, J.F., Wiggins, A., Boyle, O.D., Briggs, R.D., Chapin III, S.F., Hewitt, D.A., Preuss, P.W., Soukup, M.L. (2016). Citizen science can improve conservation science, natural resource management, and environmental protection. Biological Conservation, http://dx.doi.org/10.1016/j.biocon.2016.05.015.

Mousa, H., Ben Mokhtar, S., Hasan, O., Younes, O., Hadhoud, M., Brunie, L. (2015). Trust management and reputation systems in mobile participatory sensing applications: a survey. Computer Networks, 90, 49-73.

Musall, H. (2015). Die Zähmung des Oberrheins. In E.O. Bräunche, C. Kramer, P. Ludäscher, A. Zibat, D. Wiktorin (Ed.), Atlas Karlsruhe, 300 Jahre Stadtgeschichte in Karten und Bildern (pp. 86-87). Köln: Emons Verlag.

\footnotetext{
${ }^{11}$ www.bwstiftung.de

12 www.bw-stipendium.de
} 
Open Government Partnership (OGP) South Africa (2011). Open Government Partnership Declaration. http://www.ogp.gov.za/?q=node/17. Accessed 25 October 2016.

Regierungspräsidium Karlsruhe (Ed.) (2015). Exploring the Rhine floodplains. A family on the way in the floodplains of the river Rhine. http://www4.lubw.badenwuerttemberg.de/servlet/is/256334/. Accessed 15 October 2016.

Reichenbacher, T. (2012). Kartographie in der mobilen digitalen Welt. In D. Beineke, O. Heunecke, T. Horst, U.G.F. Kleim (Ed.), Festschrift für Univ.-Prof. Dr.-Ing. Kurt Brunner anlässlich des Ausscheidens aus dem aktiven Dienst. Schriftenreihe des Instituts für Geodäsie der Universität der Bundeswehr München, 87, 179-188.

Rip, F., Wallentin, G., Van Lammeren, R. (2014). Integrated analysis of the demand for and supply of geospatial education and training - Results of the GIN2K surveys. Lifelong Learning Programme (LLP) Erasmus Academic Network No 540409-LLP-1-2013-1BE-ERASMUS-ENW. publications/. Accessed 1 May 2015.

Schwab, K., \& Sala-i-Martín, X. (Ed.) (2015). The Global Competitiveness Report 2015-2016. Geneva: World Economic Forum.

Vogler, R. (2016). „Soziale Geokommunikation” durch Laien - (k)eine Frage der Tools? S. Hennig (Ed.), OnlineKarten im Fokus: Praxisorientierte Entwicklung und Umsetzung (pp. 105-123). Berlin: Wichmann. 